\title{
Perinatal Outcomes in Women with Intrahepatic Cholestasis of Pregnancy Receiving Ursodeoxycholic Acid - A Randomized Controlled Trial
}

\author{
Nagy M Metwally Ahmed* \\ Department of Obstetrics and Gynecology, Zagazig University, Egypt
}

Submission: December 14, 2019; Published: January 07, 2020

*Corresponding author: Nagy M Metwally Ahmed, Department of Obstetrics and Gynecology, Zagazig University, Egypt

\begin{abstract}
Objective: This trial aims at adding to the available literature, by exploring the effect of UDCA on perinatal and maternal outcomes in women with ICP.

Methods: The current randomized controlled trial was conducted at Armed Forces Hospitals of South Region. Gazan KSA, during the interval between June 2017 and August 2019. The study included pregnant women with a diagnosis of ICP. Included women were randomly allocated into one of the two groups: group I, included women who received oral UDCA 250mg twice per day; and group II, included women who did not receive UDCA (Control Group). The primary outcome was preterm delivery rates.
\end{abstract}

Result: There were a significantly lower mean itch score 1 week after initiation of treatment among women of group I when compared to women of group II. The need for additional antihistamine medication or topical emollient for itching was significantly lower among women of group I. There were no significant differences between women of both groups regarding the mode of delivery, or rates of primary PPH. The rates of preterm delivery, LBW, VLBW and IUFD were all comparable in both groups of women. The mean gestational age at delivery and the mean birth weight were not significantly different in both groups.

Conclusion: UDCA seems to be effective in reducing itching in women with ICP, without significant impact on improving perinatal outcome

Keywords: Intrahepatic cholestasis of pregnancy; Ursodeoxycholic acid; Preterm delivery; Pregnancy-specific; Perinatal mortality; Perinatal morbidity; In-utero fetal demise; Postpartum hemorrhage

Abbreviatations: ICP: Intrahepatic Cholestasis of Pregnancy; IUFD: In-Utero Fetal Demise; UDCA: Ursodeoxycholic Acid; PPH: Primary Postpartum Hemorrhage; VLBW: Very Low Birth Weight

\section{Introduction}

Intrahepatic cholestasis of pregnancy (ICP) is a pregnancyspecific condition that is associated with increased rates of perinatal mortality and morbidity [1]. The initial presentation of such a condition is usually pruritus without skin rash [2]. Although a raised serum bile acid is specific for diagnosis of ICP, clinical diagnosis relies on exclusion of other causes that can cause pruritus with or without mild elevation in liver transaminases in late pregnancy [3]. The lines of management for women with ICP in current practice includes close maternal and fetal surveillance, timely delivery at 37-38 weeks of gestation, and symptomatic treatment of itching [4]. Non-specific treatment for itching has been described for ICP-associated pruritus. Common examples include systemic or local antihistamines, and topical emollients [5].
A specific treatment, however, is needed, not only to alleviate the symptom of itching, but also to reduce the serum bile acid levels. High serum bile acid levels have been linked to the most serious adverse outcome of ICP, which is in-utero fetal demise (IUFD) [6]. Ursodeoxycholic acid (UDCA) is a naturally-occurring bile acid that is used in treatment of many hepatobiliary disorders [7]. UDCA has been used for decades in management of ICP. Guidelines from large Obstetrics and Gynecology societies and institutes recommend its use for such an indication $[3,8,9]$. Mechanisms of action include increased bile acid excretion through upregulation of metabolic enzymes and bile acid transporters in liver, increased hepatocellular secretion, and protection of hepatocytes from cytotoxicity of bile acids $[10,11]$. Whether such a reduction in 
symptoms and serum bile acid salts would improve perinatal and maternal outcomes has been a matter of debate over the last decade. Several trials and two systematic reviews have tried to answer this question [6,12]. The quality and magnitude of evidence remained weak, however. This trial aims at adding to the available literature, by exploring the effect of UDCA on perinatal and maternal outcomes in women with ICP $[13,14]$.

\section{Methods}

The current randomized controlled trial was conducted at Armed Forces Hospitals of South Region. Gazan KSA, during the interval between June 2017 and August 2019. The study protocol was in agreement to the Helsinki declaration of Ethical Medical Research. The study included pregnant women with a diagnosis of ICP. Diagnosis was made in pregnant women $\geq 28$ weeks of gestation, presenting with pruritus without skin rash, and after exclusion of other causes of pruritus and liver disorders. Serum bile acids (as specific biomarkers for ICP) were not routinely performed as it is quite costly in our institute. Women with chronic biliary disorders, chronic active hepatic disorders or known to have pruritus prior to pregnancy were not recruited in the study. Eligible women were approached and signed informed written consent before participating. Included women were randomly allocated (using a computer-generated system) into one of the two groups: group I, included women who received oral UDCA 250mg twice per day [Ursofalk®, MinaPharm - Dr. FalkGermany Hepatitis]; and group II, included women who did not receive UDCA (Control Group). Random allocation was concealed and only released after recruitment. Pruritus was semi-objectively assessed using the Itch Score 13, which was as a $100-\mathrm{mm}$ visual analogue scale for the intensity of the worst itching episode in the preceding 24 hours. Itch score was noted before onset of treatment and 1 week thereafter. The primary outcome was preterm delivery rates. Secondary maternal outcomes included improvement in itch score, need for additional anti-pruritic treatment, mode of delivery, and primary postpartum hemorrhage (PPH) rates. Secondary perinatal outcomes included rates of in-utero fetal demise (IUFD), gestational age at delivery, birth weight, rates of low birth weight (LBW, defined as birth weight $<2,500 \mathrm{~g}$ ) and very low birth weight (VLBW, defined as birth weight $<1,500 \mathrm{~g}$ ).

\section{Sample Size Justification}

Sample size was calculated using the Online Power and Sample Size Calculator, setting the power $(1-\beta)$ at 0.8 and the type- 1 error $(\alpha)$ at 0.05 . Data from a recent randomized trial 14 showed that the rates of preterm delivery in women who received UDCA and women who did not were $23 \%$ and $27 \%$, respectively. Calculation according to these values, setting the non-inferiority margin at 0.05 , produces a minimal sample size of 115 women in each group. Assuming a drop-out rate of $10 \%$ in each group, a total number of 253 women were recruited in the current trial.

\section{Statistical Methods}

Statistical analysis was performed using MedCalc $\AA$ version 7.0. Difference between two independent metric variables was analyzed using independent student's t-test as well as mean difference and its $95 \%$ confidence interval. Difference between two categorical variables was analyzed using chi-squared test as well as risk ratio and its 95\% confidence interval. Significance level was set at 0.05 .

\section{Result}

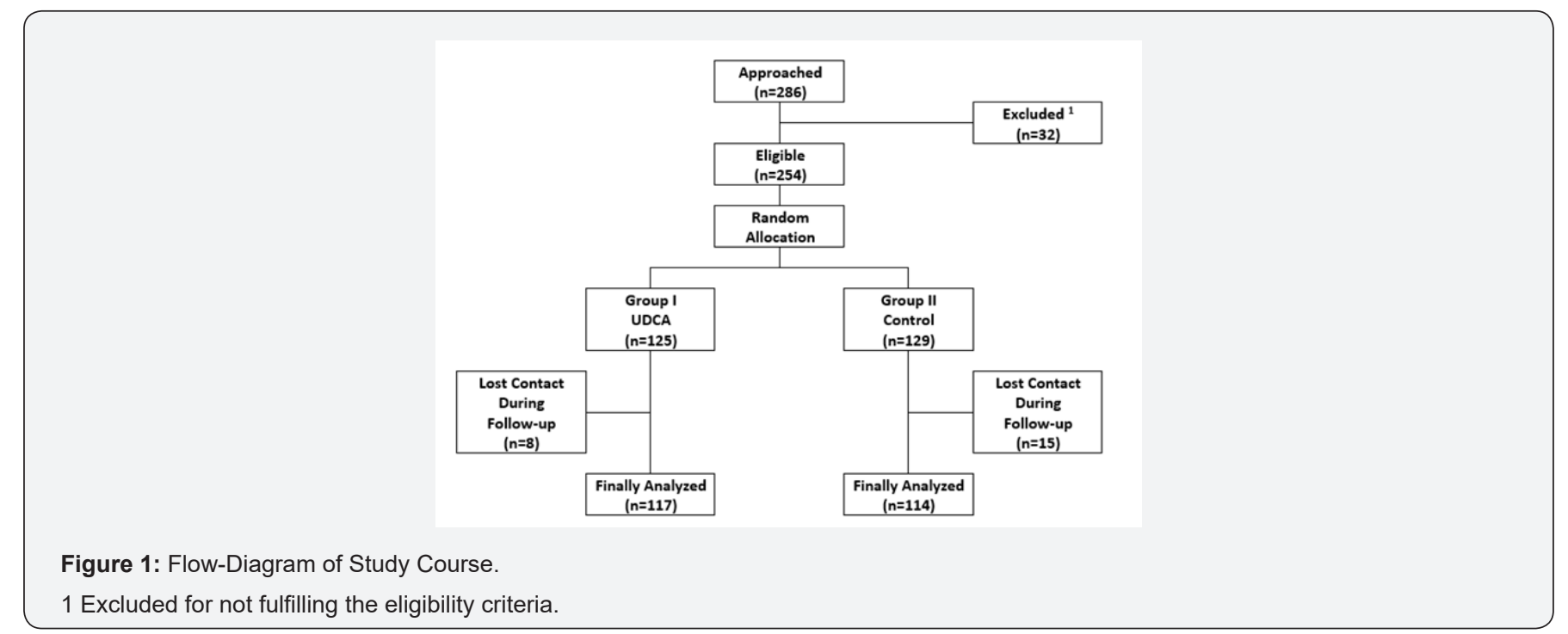

Figure 1 shows a flow-diagram of the study course. Perprotocol analysis was adopted in the current trial. There were no significant differences between women of both groups regarding age, body mass index (BMI), gestational age at presentation, prevalence of pre-existing diabetes mellitus, history of ICP in prior pregnancy(ies), and the initial itch score (Table 1). 
Table 1: Difference between Groups regarding Initial Characteristics.

\begin{tabular}{|c|c|c|c|c|}
\hline & $\begin{array}{c}\text { Group I [UDCA Group] } \\
(\mathbf{N}=\mathbf{1 1})\end{array}$ & $\begin{array}{c}\text { Group II [Control Group] } \\
\text { (N=114) }\end{array}$ & MD (95\% CI) & P \\
\hline Age (years) & $28.3 \pm 4.1$ & $28.5 \pm 4.2$ & $0.20(-0.88$ to 1.27$)$ & $0.750^{1}$ \\
\hline BMI (kg/m²) & $27.6 \pm 5.3$ & $27.5 \pm 5.2$ & $0.10(-1.26$ to 1.46$)$ & $0.885^{1}$ \\
\hline Previous ICP & $53(45.3 \%)$ & $49(43.0 \%)$ & $1.05(0.79$ to 1.41$)$ & $0.723^{2}$ \\
\hline Pre-Existing DM & $4(3.4 \%)$ & $6(5.3 \%)$ & $0.65(0.19$ to 2.24$)$ & $0.715^{2}$ \\
\hline Gestational Age (weeks) & $34.2 \pm 3.9$ & $34.7 \pm 4.1$ & $-0.5(-1.53$ to 0.54$)$ & $0.343^{1}$ \\
\hline Gestational Age <34 weeks & $51(43.6 \%)$ & $54(47.4 \%)$ & $0.92(0.69$ to 1.22$)$ & $0.564^{2}$ \\
\hline Twin Pregnancy & $6(5.1 \%)$ & $9(7.9 \%)$ & $0.65(0.24$ to 1.77$)$ & $0.394^{2}$ \\
\hline Itch Score & $56.8 \pm 9.1$ & $58.1 \pm 7.7$ & $-1.3(-3.49$ to 0.89$)$ & $0.243^{1}$ \\
\hline
\end{tabular}

Data presented as mean \pm standard deviation

BMI body mass index (calculated as weight $[\mathrm{kg}]$ divided by squared height $\left[\mathrm{m}^{2}\right]$ )

ICP intrahepatic cholestasis of pregnancy -DM diabetes mellitus -UDCA Ursodeoxycholic acid

MD $(95 \% \mathrm{Cl})$ mean difference and its $95 \%$ confidence interval

$\mathrm{RR}(95 \% \mathrm{Cl})$ risk ratio and its $95 \%$ confidence interval

1 Analysis using independent student's t-test

2 Analysis using chi-squared test

Table 2: Difference between Groups regarding Maternal Outcomes.

\begin{tabular}{|c|c|c|c|c|}
\hline & $\begin{array}{c}\text { Group I [UDCA Group] } \\
\text { (N=117) }\end{array}$ & $\begin{array}{l}\text { Group II [Control } \\
\text { Group] }(\mathrm{N}=114)\end{array}$ & MD/RR (95\% CI) & $\mathbf{P}$ \\
\hline Itch Score & $32.1 \pm 8.8$ & $57.7 \pm 6.2$ & 25.6 (23.62 to 27.6$)$ & $<0.001^{1}$ \\
\hline \multicolumn{5}{|c|}{ Need for Additional Anti-Itching Treatment } \\
\hline Antihistamine & $51(43.6 \%)$ & $81(71.1 \%)$ & $0.61(0.48$ to 0.78$)$ & $<0.001^{2}$ \\
\hline Topical emollient & $60(51.3 \%)$ & $74(64.9 \%)$ & 0.79 (0.63 to 0.99$)$ & $0.036^{2}$ \\
\hline \multicolumn{5}{|l|}{ Mode of Delivery } \\
\hline Vaginal Delivery & $42(35.9 \%)$ & $48(42.1 \%)$ & & \\
\hline Cesarean Delivery & $75(64.1 \%)$ & $66(57.9 \%)$ & $0.85(0.62$ to 1.18$)$ & $0.333^{2}$ \\
\hline Primary PPH & $4(3.4 \%)$ & $6(5.3 \%)$ & $0.65(0.19$ to 2.24$)$ & $0.715^{2}$ \\
\hline
\end{tabular}

Data presented as mean \pm standard deviation; or frequency (percentage)

$\mathrm{PPH}$ postpartum hemorrhage

UDCA Ursodeoxycholic acid

MD $(95 \% \mathrm{Cl})$ mean difference and their 95\% confidence interval

RR $(95 \% \mathrm{Cl})$ risk ratio and their $95 \%$ confidence interval

1 Analysis using independent student's t-test

2 Analysis using chi-squared test

There were a significantly lower mean itch score 1 week after initiation of treatment among women of group I when compared to women of group II. The need for additional antihistamine medication or topical emollient for itching was significantly lower among women of group I. There were no significant differences between women of both groups regarding the mode of delivery, or rates of primary PPH (Table 2). The rates of preterm delivery, LBW, VLBW and IUFD were all comparable in both groups of women. The mean gestational age at delivery and the mean birth weight were not significantly different in both groups (Table 3). 
Table 3: Difference between Groups regarding Pregnancy and Miscarriage Outcomes.

\begin{tabular}{|c|c|c|c|c|}
\hline & $\begin{array}{l}\text { Group I [UDCA Group] } \\
\text { (N=117) }\end{array}$ & $\begin{array}{l}\text { Group II [Control Group] } \\
\text { (N=114) }\end{array}$ & MD/RR (95\% CI) & $\mathbf{P}$ \\
\hline IUFD & $2(1.7 \%)$ & $5(4.4 \%)$ & $0.39(0.08$ to 1.97$)$ & $0.432^{1}$ \\
\hline Preterm Delivery & $21(17.9 \%)$ & $26(22.8 \%)$ & $0.79(0.47$ to 1.32$)$ & $0.359^{1}$ \\
\hline Gestational Age at Delivery (weeks) & $37.4 \pm 1.8$ & $37.1 \pm 2.1$ & $0.3(-0.21$ to 0.81$)$ & $0.245^{2}$ \\
\hline Birth weight (g) & $3212.3 \pm 412.1$ & $3158.1 \pm 319.7$ & $54.2(-41.6$ to 149.9$)$ & $0.266^{2}$ \\
\hline LBW & $6(5.1 \%)$ & $9(7.9 \%)$ & $0.65(0.24$ to 1.77$)$ & $0.394^{1}$ \\
\hline VLBW & $1(0.9 \%)$ & $3(2.6 \%)$ & $0.32(0.03$ to 3.08$)$ & $0.596^{1}$ \\
\hline
\end{tabular}

Data presented as mean \pm standard deviation; or frequency (percentage)

IUFD in utero fetal demise

LBW low birth weight $(<2,500 \mathrm{~g})$

VLBW very low birth weight $(<1,500 \mathrm{~g})$

UDCA Ursodeoxycholic acid

MD $(95 \% \mathrm{Cl})$ mean difference and their 95\% confidence interval

$\mathrm{RR}(95 \% \mathrm{Cl})$ risk ratio and their $95 \%$ confidence interval

1 Analysis using chi-squared test

2 Analysis using independent student's t-test

\section{Discussion}

The current trial showed that UDCA treatment at a dose of $250 \mathrm{mg}$ twice per day was effective in reducing pruritus in women with ICP; yet, not effective in improving perinatal outcomes in terms of rates of preterm delivery, IUFD, LBW and VLBW. The results of the primary outcome was in agreement with a recent large multicenter randomized trial 15 , which showed no significant impact of UDCA on perinatal outcomes: IUFD, preterm delivery and neonatal ICU admission. In addition, this latter trial, in contrast to the current one, showed no clinically-meaningful improvement of itch score 15. The improvement in pruritus reported in women who received UDCA in the current trial is both statistically significant and clinically meaningful [initial itch score: $56.8 \pm 9.1$ vs. $58.1 \pm 7.7$, respectively; after treatment: $32.1 \pm 8.8$ vs. $57.7 \pm 6.2$, respectively]. It has been plausibly defined that a clinically meaningful improvement in the mean itch score would be at least $30 \mathrm{~mm}$ [6]. Figures of the current trial are close to that definition. The rates of preterm delivery in the current trial [17.9\% in group I; $22.8 \%$ in group II; overall rate of $20.3 \%$ ] were rather different from those reported in the large previous trial [11\%] 15 and in the Cochrane systematic review [44\%] [6]. These obvious and documented heterogeneity in outcomes of both ICP per se, and UDCA treatment reflect two possible facts: first, ICP is not a single homogeneous entity; second: UDCA has no unified action in all groups of women 15. A possible explanation for that is the marked variation in serum bile acid concentrations reported in women with a diagnosis of ICP. It has been shown in a recent meta-analysis published in 2019 that the risks of adverse perinatal outcomes are correlated to the serum bile acid concentration [risks of stillbirth and preterm birth significantly rose when peak serum bile acid concentration exceeded $100 \mu \mathrm{mol} / \mathrm{L}$ and $40 \mu \mathrm{mol} / \mathrm{L}$ $\mu \mathrm{mol} / \mathrm{L}$, respectively] [1]. Limitations of the study: A remarkable limitation of the current study is the lack of using serum bile acid levels as diagnostic or prognostic marker. Practically-speaking, serum bile acid assay is not routinely performed to diagnose ICP in our institute for a couple of reasons: first, the assay is costly; and second, the diagnosis of ICP is one of exclusion. The latest greentop guideline published by the Royal College of Obstetricians and Gynaecologists (RCOG) stated that ICP is diagnosed when otherwise unexplained pruritus in pregnancy and resolve after delivery; abnormal liver function tests and/or elevated bile acids are not essential for diagnosis; and normal serum levels of bile acids does not exclude diagnosis [3]. A second limitation is the low incidence of major adverse outcomes, particularly IUFD and stillbirth, which made the current study underpowered to estimate any significant difference in these outcomes. A quite large sample size (of thousands of cases) is needed to overcome this latter limitation; only multicenter studies or meta-analyses is able to achieve such a power.

\section{Conclusion}

UDCA seems to be effective in reducing itching in women with ICP, without significant impact on improving perinatal outcome

\section{References}

1. Tomic V, Tomic J, Klaic DZ, Kasum M, Kuna K, et al. (2015) Oral dydrogesterone versus vaginal progesterone gel in the luteal phase support: randomized controlled trial. Eur J Obstet Gynecol Reprod Biol 186: 49-53.

2. Ovadia C, Seed PT, Sklavounos A, Geenes V, Di Ilio C, et al. (2019) Association of adverse perinatal outcomes of intrahepatic cholestasis of pregnancy with biochemical markers: results of aggregate and individual patient data meta-analyses. Lancet 393(10174): 899-909. 
3. Royal College of Obstetricians and Gynaecologists (ROCG) (2011) Obstetric Cholestasis (Green Top Guideline No. 43).

4. Roncaglia N, Arreghini A, Locatelli A, Bellini P, Andreotti C, et al. (2002) Obstetric cholestasis: outcome with active management. Eur J Obstet Gynecol Reprod Biol 100(2): 167-170.

5. Jenkins JK, Boothby LA (2002) Treatment of itching associated with intrahepatic cholestasis of pregnancy. Ann Pharmacother 36(9): 1462-1465

6. Gurung V, Middleton P, Milan SJ, Hague W, Thornton JG, et al. (2013) Interventions for treating cholestasis in pregnancy. Cochrane Database Syst Rev 6: CD000493.

7. Carey EJ, Lindor KD (2012) Current pharmacotherapy for cholestatic liver disease. Expert Opin Pharmacother 13(17): 2473-2484.

8. Williamson C, Geenes V (2014) Intrahepatic cholestasis of pregnancy. Obstet Gynecol 124(1): 120-133.

9. Gabzdyl EM, Schlaeger JM (2015) Intrahepatic cholestasis of pregnancy: a critical clinical review. J Perinat Neonatal Nurs 29(1): 41-50.
10. Roma MG, Toledo FD, Boaglio AC, Basiglio CL, Crocenzi FA, et al. (2011) Ursodeoxycholic acid in cholestasis: linking action mechanisms to therapeutic applications. Clin Sci (Lond) 121(12): 523-544.

11. Beuers U (2006) Drug insight: mechanisms and sites of action of ursodeoxycholic acid in cholestasis. Nat Clin Pract Gastroenterol Hepatol 3(6): 318-328.

12. Bacq Y, Sentilhes L, Reyes HB, Glantz A, Kondrackiene J, et al. (2012) Efficacy of ursodeoxycholic acid in treating intrahepatic cholestasis of pregnancy: a meta-analysis. Gastroenterology 143(6): 1492-1501.

13. Phan NQ, Blome C, Fritz F, Gerss J, Reich A, et al. (2012) Assessment of pruritus intensity: prospective study on validity and reliability of the visual analogue scale, numerical rating scale and verbal rating scale in 471 patients with chronic pruritus. Acta Derm Venereol 92(5): 502507.

14. Chappell LC, Bell JL, Smith A, Linsell L, Juszczak E, et al. (2019) Ursodeoxycholic acid versus placebo in women with intrahepatic cholestasis of pregnancy (PITCHES): a randomised controlled trial. Lancet 394(10201): 849-860.

\section{Your next submission with Juniper Publishers will reach you the below assets}

- Quality Editorial service

- Swift Peer Review

- Reprints availability

- E-prints Service

- Manuscript Podcast for convenient understanding

- Global attainment for your research

- Manuscript accessibility in different formats ( Pdf, E-pub, Full Tsext, Audio)

- Unceasing customer service

Track the below URL for one-step submission https://juniperpublishers.com/online-submission.php 